\title{
TFEE Measurement, Decomposition and Influencing Factors Analysis of Eight Economic Regions in China
}

\author{
Feng Ren*, Xin Yu \\ School of Business and Administration, North China Electric Power University, \\ Baoding 071003, Hebei Province, China
}

Received: 5 January 2020

Accepted: 5 April 2020

\begin{abstract}
It is of great significance to improve Total Factor Energy Efficiency (TFEE) for China's energy saving, emission reduction and ecological protection. This paper focuses on the calculation and decomposition of TFEE of eight economic regions in China considering the effects of undesirable outputs. The TFEE values of the eight economic regions in China are calculated via the input-oriented radial CRS super-efficiency SBM model. In order to overcome the shortcomings of the traditional ML index, this paper firstly builds an improved ML index using MinDS function, then decomposes the TFEE values through Zofio decomposition analysis method, and then identifies the driving factors of TFEE via Tobit model, and finally clarifies the path of improving TFEE in the economic regions. The findings show that the TFEE values of the eight economic regions in China are basically higher in the southeast and lower in the northwest. The dominant factor affecting the TFEE values in the eight economic regions is industrial structure, followed by technological development level. The research conclusions of this paper can provide reference for the formulation of policies for energy conservation and ecological protection.
\end{abstract}

Keywords: TFEE, Super-efficiency SBM, ML Index, Zofio Decomposition, Tobit Model

\section{Introduction}

In recent years, energy efficiency, carbon emission reduction and ecological protection have been the hottest issues globally. China's high-speed growth of economy is at the cost of inefficient consumption of fossil energy, with releasing large quantities of greenhouse gases such as carbon dioxide, which leads to the continuous

\footnotetext{
*e-mail: 51851321@ncepu.edu.cn
}

deterioration of the ecological environment [1-3]. For China, the inefficient use of fossil energy is an critically important cause of carbon emission increase and ecological deterioration. So, improving China's energy efficiency can help reduce the consumption of fossil energy, and accordingly reduce carbon emissions and improve the ecological environment. Therefore, it is of great positive significance to study China's energy efficiency.

In 2017, China's GDP reached 82.71 trillion RMB [4], its energy consumption reached 3132.2 million tones 
oil equivalent, accounting for $23.2 \%$ of the world's total (Total North America 20.5\%; Total Europe, 14.6\%), and China was still the largest energy consumer in the world [5]. According the BP's forecasting, despite slowing energy demand growth, China still consumes around one quarter of world energy in 2040. China's share in global energy demand will rise from $23 \%$ in 2016 to $24 \%$ in 2040 , while its growth contributes $27 \%$ to the world's net increase [5].

China is not only the largest energy consumer, but also the largest carbon emitter. In 2017, China's carbon dioxide emission reached 9232.6 million tones, accounting for $27.6 \%$ of the world's total. China's carbon dioxide emission exceeded the total emission of North America, also overnumbered the total emission of Europe, and was slightly lower than the total emission of G7 (the seven most developed countries in the world) [6]. Detailed information on carbon emissions can be found in Table 1 .

China's ecological environment has also been seriously deteriorated due to the excessive use of fossil energy. In recent years, Chinese central government has also been committed to solving the problems of ecological deterioration, and has formulated national plans for this purpose. China regulated the energy consumption intensity per unit GDP as a binding index in its" $11^{\text {th }}$ Five-Year Plan"; declared the total energy consumption should be reasonably controlled in its , $12^{\text {th }}$ Five-Year Plan"; and proposed the implementation of the „double control“ action of total energy consumption and consumption intensity in its "13 $13^{\text {th }}$ Five-Year Plan“.

In conclusion, it is urgent to study how to improve the total factor energy efficiency (TFEE) in China in order to implement the major measures of the national energy strategy and for the sustainable development of the economy and society.

According to the geographical location, China can be divided into eight major economic regions, namely, the northeast region, the northern coastal region, the eastern coastal region, the southern coastal region, the middle reaches of the Yellow River, the middle reaches of the Yangtze River, the southwest region, and the northwest region. In order to seek rapid, stable and balanced economic development, China has been

Table 1. Shares of the Global $\mathrm{CO}_{2}$ Emissions in 2017.

\begin{tabular}{|c|c|c|c|}
\hline Country & Share & Country & Share \\
\hline China & $23.2 \%$ & Italy & $1.0 \%$ \\
\hline US & $15.2 \%$ & Russia & $4.6 \%$ \\
\hline Canada & $1.7 \%$ & Japan & $3.5 \%$ \\
\hline UK & $1.2 \%$ & Total North America & $18.3 \%$ \\
\hline Germany & $2.3 \%$ & Total Europe & $12.4 \%$ \\
\hline France & $1.0 \%$ & Total G7 & $25.9 \%$ \\
\hline
\end{tabular}

(Note: The G7 countries include US, UK, France, Germany, Italy, Canada, and Japan.) implementing the strategies of ,take-off of the eastern region, development of the western region, revitalization of the northeast region, and rise of the central region" since 2010, setting different development goals and formulating different support policies for different regions. The significance of studying TFEE of the eight economic regions in China can be understood from the following aspects.

(a) Relieve the pressure of energy shortage. China is a country with relative energy shortage. Improving energy efficiency can greatly reduce energy demand and relieve the pressure of energy shortage, which is conducive to the implementation of the national energy security strategy. (b) Reduce carbon emissions. China is facing pressures from international communities to reduce carbon emissions, and has set a carbon emission reduction target for 2030. At the Paris Climate Conference in 2015, Chinese government solemnly pledged to reduce its carbon intensity by more than $60 \%$ by 2030 compared with 2005 . Improving energy efficiency can reduce carbon emissions and contribute to the realization of China's carbon emission reduction target. (c) Improve the ecological environment. Due to the extensive use of fossil energy (especially coal), the ecological environment is deteriorating and severe toxic haze frequently occurs in many areas of China. Improving energy efficiency can reduce the consumption of fossil energy and help improve the ecological environment. (d) Provide policy recommendations. It is beneficial to study the total factor energy efficiency (TFEE) of different economic regions for the central government to carry out macro-control and formulate more scientific energy policies at the national level. Meanwhile, it is helpful to optimize the energy structure and the industrial structure, enhance regional competitiveness, and realize the sustainable development of economy and society at the regional level.

Generally speaking, the study of energy efficiency can be divided into two stages: single factor energy efficiency stage and total factor energy efficiency (TFEE) stage. Patterson and Shi et al. are the representative scholars in single factor energy research [7-8]. Patterson [7] first gave the definition of energy efficiency and pointed out that "energy intensity" can most directly reflect energy efficiency. Shi [8] characterized energy efficiency by the reciprocal of energy intensity. Because of the defects of single factor energy efficiency, $\mathrm{Hu}$ and Wang [9] put forward the concept of total factor energy efficiency (TFEE), that is, "the ratio of actual output to maximum possible output under the condition of constant energy and other inputs; or the ratio of target energy consumption to actual energy consumption under the condition of constant outputs".

As for the study of total factor energy efficiency (TFEE), researchers mainly focus on the measurement of energy efficiency and the analysis of influencing factors. The main research methods include index decomposition method [10-13], data envelopment 
analysis (DEA) [14-18], stochastic frontier analysis (SFA) [19-23] and Tobit model [24-27], etc. With the deterioration of the environment, more and more attention has been paid to the study of TFEE considering undesirable outputs [28-32].

In terms of calculation methods, more and more researchers chose DEA method to calculate TFEE because of the strict assumptions for using SFA, as well as its inconvenience to calculate. However, the traditional DEA method has a serious defect. If several decision-making units are efficient simultaneously, then the traditional DEA model cannot further distinguish the differences between these efficient decision-making units. Therefore, Anderson and Petersen [33] introduced a super-efficient DEA model. The influencing factors of TFEE mainly involve energy consumption structure [34-35], industrial structure [36-37], environmental regulation [36,38], energy price [39], international trade [37, 40-41], technological progress [39], human resources [42], and economic ownership [43], etc.

It can be proved that DEA efficiency is equivalent to the Pareto efficiency of the corresponding multiobjective programming. The productivity index is generally used as an alternative of TFEE in academia. Malmquist index ( $\mathrm{M}$ index) [44-46] and Malmquist Luenberger index (ML index) [47-50] are the most commonly used indicators to measure the productivity index. ML index is much more widely used because of its feasibility to deal with undesirable output. The TFEE of the eight major economic regions involves undesirable outputs, so ML index is much more appropriate for the research in this paper.

Although there are many references to TFEE home and abroad, few sources have been found on TFEE in China's eight economic regions. The main objective of this paper is to take the eight economic regions as a case to analyze the estimation, decomposition and influencing factors analysis of TFEE. Firstly, we use super-efficiency SBM model to calculate the TFEE values of the eight economic regions; secondly, use MinDS to calculate the ML index of China's eight economic regions, and then decompose the ML index via Zofio method; thirdly, the Tobit model is used to find out the dominant factors affecting the TFEE of the eight economic regions; and finally, discussions are made and some recommendations are provided to improve the TFEE of the eight economic regions. Relevant research results show that the method used in this paper are scientific and effective for the measurement, decomposition and influencing factors analysis of TFEE in China.

\section{Methodology}

\section{MinDS Model}

The MinDS model proposed by Aparicio et al. [51] has many advantages. For example, it can solve the problems that Directional Distance Function (DDF) model cannot calculate the amount of improvement and unreasonable weak disposal of the undesirable output. It can also correct the irrationality of SBM (Slacks-based Model) in calculating efficiency by using the farthest projection point on the front surface. In addition, Wang et al. [52] believed that the results from MinDS model are more meaningful for policy-making.

Suppose there are $n$ decision-making units, and each decision-making unit has $m$ inputs, $d$ desirable outputs and $u$ undesirable outputs. Define the input variables for the $t$ period as $X^{t}=\left(x_{1}{ }^{t}, x_{2}{ }^{t}, \ldots, x_{m}{ }^{t}\right) \in$ $R_{m \times n}$, the desirable variables as $Y^{t G}=\left(y_{1}{ }^{t G}, y_{2}{ }^{t G}, \ldots, y_{d}{ }^{t G}\right)$ $\in R_{d \times n}$, and the undesirable variables as $Y^{t B}=\left(y_{1}{ }^{t B}, y_{2}{ }^{t B}\right.$, ..., $\left.y_{u}{ }^{t B}\right) \in R_{u \times n}$. Assume the decision-making unit to be estimated is $D M U_{0}{ }^{t}=\left(x_{0}{ }^{t}, y_{0}{ }^{t G}, y_{0}{ }^{t B}\right)$, then MinDS model can be expressed as follows:

$$
\begin{aligned}
& \min \left[\left(\sum_{a=1}^{m} s_{a 0}^{t x^{-}}+\sum_{b=1}^{d} s_{b 0}^{t y^{+}}+\sum_{c=1}^{u} s_{c 0}^{t y^{-}}\right)+M\left(\sum_{a=1}^{m} \hat{s}_{a 0}^{t x^{-}}+\sum_{b=1}^{d} \hat{s}_{b 0}^{t y^{+}}+\sum_{c=1}^{u} \hat{s}_{c 0}^{t y^{-}}\right)\right] \\
& s_{a 0}^{t x^{-}} \geq 0, a=1,2, \ldots, m \\
& s_{b 0}^{t y^{+}} \geq 0, b=1,2, \ldots, d \\
& s_{c 0}^{t y^{-}} \geq 0, c=1,2, \ldots, u \\
& \max \left(\sum_{a=1}^{m} \hat{s}_{a 0}^{t x^{-}}+\sum_{b=1}^{d} \hat{s}_{b 0}^{t y^{+}}+\sum_{c=1}^{u} \hat{s}_{c 0}^{t y^{-}}\right) \\
& \quad \sum_{j=1}^{n} \lambda_{j}^{t} x_{a j}^{t}+\hat{s}_{a 0}^{t x^{-}}=x_{a 0}^{t}-s_{a 0}^{t x^{-}} \\
& \quad \sum_{j=1}^{n} \lambda_{j}^{t} y_{a j}^{t G}-\hat{s}_{b 0}^{t t^{+}}=y_{a 0}^{t G}+s_{b 0}^{t t^{+}} \\
& \quad \sum_{j=1}^{n} \lambda_{j}^{t} y_{a j}^{t B}+\hat{s}_{c 0}^{t y^{-}}=y_{a 0}^{t B}-s_{c 0}^{t y^{-}} \\
& \lambda_{j}^{t} \geq 0, \hat{s}_{a 0}^{t x^{-}} \geq 0, \hat{s}_{b 0}^{t y^{+}} \geq 0, \hat{s}_{c 0}^{t y^{-}} \geq 0
\end{aligned}
$$

Formula (1) is a two-level programming model, in which $s_{a 0}{ }^{t x-}, s_{b 0}{ }^{t y+}, s_{c 0}{ }^{t y-}$ represent the slack variables of the inputs, the desirable outputs, and the undesirable outputs in the first level programming in the $\mathrm{t}$ period, respectively. $\hat{s}_{a 0}^{t x-}, \hat{s}_{b 0}^{t y+}$ and $\hat{s}_{c 0}{ }^{t y-}$ represent the slack variables of the inputs, the desirable outputs, and the undesirable outputs in the second level programming in the $t$ period, respectively. $M$ is a sufficiently large positive number. According to the reference [53], the comprehensive efficiency of the $t$ period is defined as Formula (2):

$$
S_{0}^{t}\left(x_{j}^{t}, y_{j}^{t G}, y_{j}^{t B}\right)=\frac{1-\frac{1}{m} \sum_{a=1}^{m}\left(s_{a 0}^{t x^{-}}+\hat{s}_{a 0}^{t x^{-}}\right) / x_{a 0}^{t}}{1+\frac{1}{d} \sum_{b=1}^{d}\left(s_{b 0}^{t y^{+}}+\hat{s}_{b 0}^{t y^{+}}\right) / y_{b 0}^{t G}+\frac{1}{u} \sum_{c=1}^{u}\left(s_{c 0}^{t y^{-}}+s_{c 0}^{t y^{-}}\right) / y_{c 0}^{t B}}
$$

\section{Constructing ML Index}

The Malmquist index proposed by Färe does not consider the undesirable outputs. In this paper, we use 
MinDS function to construct the ML index considering the undesirable outputs. The ML index is shown as Formula (3):

$$
M L_{t}^{t+1}=\left[\frac{S_{0}^{t}\left(x_{j}^{t}, y_{j}^{t G}, y_{j}^{t B}\right)}{S_{0}^{t}\left(x_{j}^{t+1}, y_{j}^{(t+1) G}, y_{j}^{(t+1) B}\right)} \times \frac{S_{0}^{t+1}\left(x_{j}^{t}, y_{j}^{t G}, y_{j}^{t B}\right)}{S_{0}^{t+1}\left(x_{j}^{t+1}, y_{j}^{(t+1) G}, y_{j}^{(t+1) B}\right)}\right]^{\frac{1}{2}}
$$

At present, productivity decomposition models mainly include FGLR decomposition, FGNZ decomposition, RD decomposition and Zofio decomposition, in which Zofio decomposition is the most complete and in-depth ML decomposition method. Zofio [54] further decomposed technology change (TECH) into pure technology change (PTC) and scale technology change (STC). The Zofio decomposition formula is as follows:

$$
\begin{aligned}
M L_{t}^{t+1} & =E F F C_{t}^{t+1} \times T E C_{t}^{t+1} \\
& =P E C_{t}^{t+1} \times S E C_{t}^{t+1} \times T E C_{t}^{t+1} \\
& =P E C_{t}^{t+1} \times S E C_{t}^{t+1} \times P T C_{t}^{t+1} \times S T C_{t}^{t+1}
\end{aligned}
$$

...where,

$$
\begin{gathered}
E F F C_{t}^{t+1}=\frac{S_{0, C R S}^{t}\left(x_{j}^{t}, y_{j}^{t G}, y_{j}^{t B}\right)}{S_{0, C R S}^{t+1}\left(x_{j}^{t+1}, y_{j}^{(t+1) G}, y_{j}^{(t+1) B}\right)} \\
T E C_{t}^{t+1}=\left[\frac{S_{0, C R S}^{t+1}\left(x_{j}^{t}, y_{j}^{t G}, y_{j}^{t B}\right)}{S_{0, C R S}^{t}\left(x_{j}^{t}, y_{j}^{t G}, y_{j}^{t B}\right)} \times \frac{S_{0, C R S}^{t+1}\left(x_{j}^{t+1}, y_{j}^{(t+1) G}, y_{j}^{(t+1) B}\right)}{S_{0, C R S}^{t}\left(x_{j}^{t+1}, y_{j}^{(t+1) G}, y_{j}^{(t+1) B}\right)}\right]^{\frac{1}{2}} \\
P E C_{t}^{t+1}=\frac{S_{0, V R S}^{t}\left(x_{j}^{t}, y_{j}^{t G}, y_{j}^{t B}\right)}{S_{0, V R S}^{t+1}\left(x_{j}^{t+1}, y_{j}^{(t+1) G}, y_{j}^{(t+1) B}\right)} \\
S E C_{t}^{t+1}=\frac{S_{0, C R S}^{t}\left(x_{j}^{t}, y_{j}^{t G}, y_{j}^{t B}\right)}{S_{0, V R S}^{t}\left(x_{j}^{t}, y_{j}^{t G}, y_{j}^{t B}\right)} \times \frac{S_{0, V R S}^{t+1}\left(x_{j}^{t+1}, y_{j}^{(t+1) G}, y_{j}^{(t+1) B}\right)}{S_{0, C R S}^{t+1}\left(x_{j}^{t+1}, y_{j}^{(t+1) G}, y_{j}^{(t+1) B}\right)}
\end{gathered}
$$

$$
P T C_{t}^{t+1}=\left[\frac{S_{0, V R S}^{t}\left(x_{j}^{t}, y_{j}^{t G}, y_{j}^{t B}\right)}{S_{0, V R S}^{t+1}\left(x_{j}^{t}, y_{j}^{t G}, y_{j}^{t B}\right)} \times \frac{S_{0, V R S}^{t}\left(x_{j}^{t+1}, y_{j}^{(t+1) G}, y_{j}^{(t+1) B}\right)}{S_{0, V R S}^{t+1}\left(x_{j}^{t+1}, y_{j}^{(t+1) G}, y_{j}^{(t+1) B}\right)}\right]^{\frac{1}{2}}
$$

$$
\begin{gathered}
S T C_{t}^{t+1}=\left[\frac{S_{0, C R S}^{t+1}\left(x_{j}^{t}, y_{j}^{t G}, y_{j}^{t B}\right)}{S_{0, C R S}^{t}\left(x_{j}^{t}, y_{j}^{t G}, y_{j}^{t B}\right)} \times \frac{S_{0, C R S}^{t+1}\left(x_{j}^{t+1}, y_{j}^{(t+1) G}, y_{j}^{(t+1) B}\right)}{S_{0, C R S}^{t}\left(x_{j}^{t+1}, y_{j}^{(t+1) G}, y_{j}^{(t+1) B}\right)}\right. \\
\left.\quad \times \frac{S_{0, V R S}^{t+1}\left(x_{j}^{t}, y_{j}^{t G}, y_{j}^{t B}\right)}{S_{0, V R S}^{t}\left(x_{j}^{t}, y_{j}^{t G}, y_{j}^{t B}\right)} \times \frac{S_{0, V R S}^{t+1}\left(x_{j}^{t+1}, y_{j}^{(t+1) G}, y_{j}^{(t+1) B}\right)}{S_{0, V R S}^{t}\left(x_{j}^{t+1}, y_{j}^{(t+1) G}, y_{j}^{(t+1) B}\right)}\right]^{\frac{1}{2}}
\end{gathered}
$$

Where, PEC, SEC, PTC and STC respectively indicate the change of management level, the change of scale economy, the change of technology, and the deviation of technology from the optimal scale. If ML index is greater than 1, then it represents progress; if ML index is less than 1, then it represents retrogression; and if ML index is equal to 1 , then it represents no change [55].

\section{Tobit Model}

In order to study the impacts of various factors on energy efficiency, panel data regression analysis is needed. Tobit model is often used for regression analysis of the influencing factors of energy efficiency, because it can deal with restricted dependent variables and truncated dependent variables. Tobit model is as follows:

$$
Y=\max \{0, \alpha+\beta X+\varepsilon\}
$$

...where $\mathrm{Y}$ is the truncated dependent variable vector; $\mathrm{X}$ is the independent variable vector; $\alpha$ is the intercept term vector; $\beta$ is the regression parameter vector; Perturbation term $\varepsilon \sim N\left(0, \sigma^{2}\right)$.

In Tobit regression model, the efficiency values are truncated discrete data. When the dependent variable obeys partially continuous distribution or partially discrete distribution, the result obtained from ordinary least squares (OLS) estimation is biased. So, maximum likelihood estimation is generally used to estimate the parameters in Tobit model. The specific operation process of maximum likelihood estimation can be referred to literature [56].

\section{Results and Discussion}

\section{Data Description}

Panel data from 2001 to 2016 of the eight major economic regions in China are collected from the Statistical Yearbooks issued by China's National Bureau of Statistics. Several missing data are supplemented by using interpolation or GM $(1,1)$ forecasting. The input variables in the model include capital, labor and energy, and the output variables include one desirable output (GDP) and two undesirable outputs $\left(\mathrm{CO}_{2}\right.$ and $\left.\mathrm{SO}_{2}\right)$. In this study, Tibet autonomous region is excluded due to the lack of data. Descriptive statistics of indicators in 30 provincial administrative regions are shown in Table 2.

(1) Capital. Organization for Economic Cooperation and Development (OECD) suggests measuring efficiency and productivity with capital services. Considering that it is very difficult to obtain capital service data, this paper takes the whole society's asset investment as a substitute index for capital service, as with similar studies.

(2) Labor. This article uses the total number of employees as labor input. The total number of employees includes the numbers of people employed in urban units, in private enterprises, and by individuals. 
Table 2. Descriptive Statistics of Index.

\begin{tabular}{|c|c|c|c|c|c|c|}
\hline & Labor & Capital & Energy & GDP & $\mathrm{SO}_{2}$ & $\mathrm{CO}_{2}$ \\
\hline Mean & 984.38 & 8252.59 & 16176.41 & 8361.64 & 749669.08 & 10888.83 \\
\hline Maximum & 5595.00 & 53323 & 75954.00 & 47140 & 2023737.00 & 69434.00 \\
\hline Minimum & 78.00 & 191.00 & 772.00 & 300.00 & 16958.00 & 399.00 \\
\hline Std. Dev. & 793.63 & 9000.05 & 12289.29 & 7622.82 & 465200.05 & 9767.40 \\
\hline Skewness & 2.17 & 1.92 & 1.57 & 1.93 & 0.51 & 2.13 \\
\hline Kurtosis & 6.63 & 4.30 & 2.85 & 4.63 & -0.61 & 5.80 \\
\hline
\end{tabular}

(3) Energy. This paper selects total consumption of energy as energy input. The total consumption of energy includes coal consumption, coke consumption, crude oil consumption, gasoline consumption, kerosene consumption, diesel consumption, fuel oil consumption, natural gas consumption, and electricity consumption. All kinds of energies are converted into standard coal in this study.

(4) GDP. This paper regards GDP as a desirable output and uses 2001 as the benchmark to collate GDP data.

(5) $\mathrm{CO}_{2}$. The $\mathrm{CO}_{2}$ emission mentioned in this paper is energy-related emission. Since there is no official figure of $\mathrm{CO}_{2}$ emission in China, this study uses $\mathrm{CO}_{2}$ emission coefficients of different kinds of energies to calculate $\mathrm{CO}_{2}$ emissions, and then adds them up to obtain the total $\mathrm{CO}_{2}$ emission.
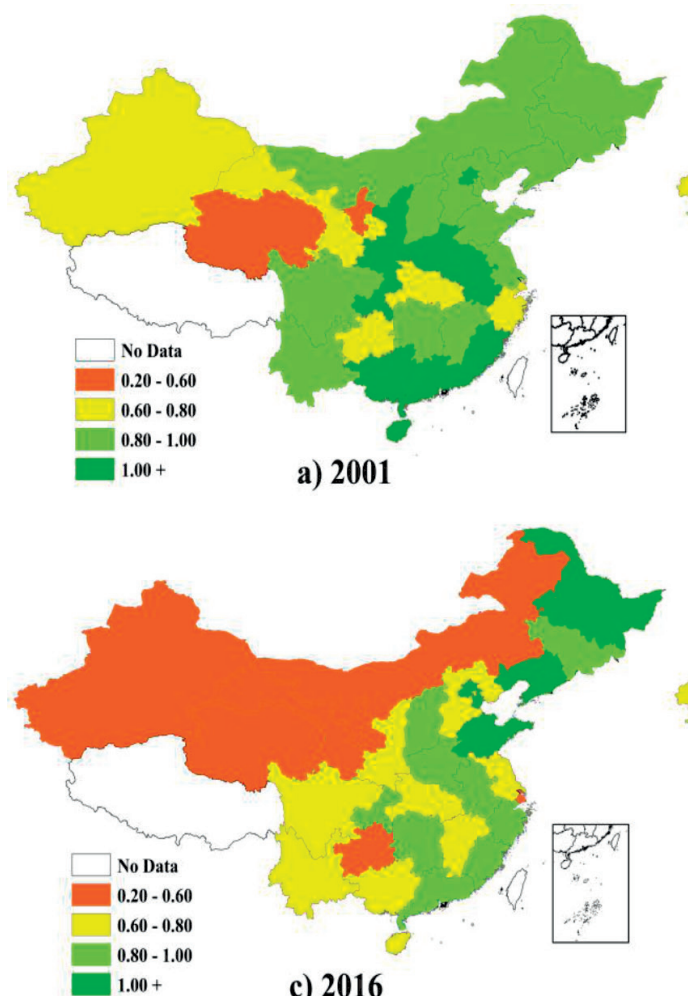

c) 2016
(6) $\mathrm{SO}_{2}$. The $\mathrm{SO}_{2}$ emission data used in this paper are directly selected from the official statistics released by the China Bureau of Statistics.

\section{Results Analysis}

Firstly, the input-oriented radial CRS superefficiency SBM model is used to calculate the total factor energy efficiency (TFEE) values of 30 provinces in China. Since the data used in this study are panel data, the TFEE values of all provinces can be calculated by setting the Window width to 1 via the Window method in MaxDEA, and then TFEE values over years of the eight major economic regions can be obtained by using the geometric averaging method. Secondly, the ML index of China's eight major economic regions is worked out, and Zofio decomposition is carried out on
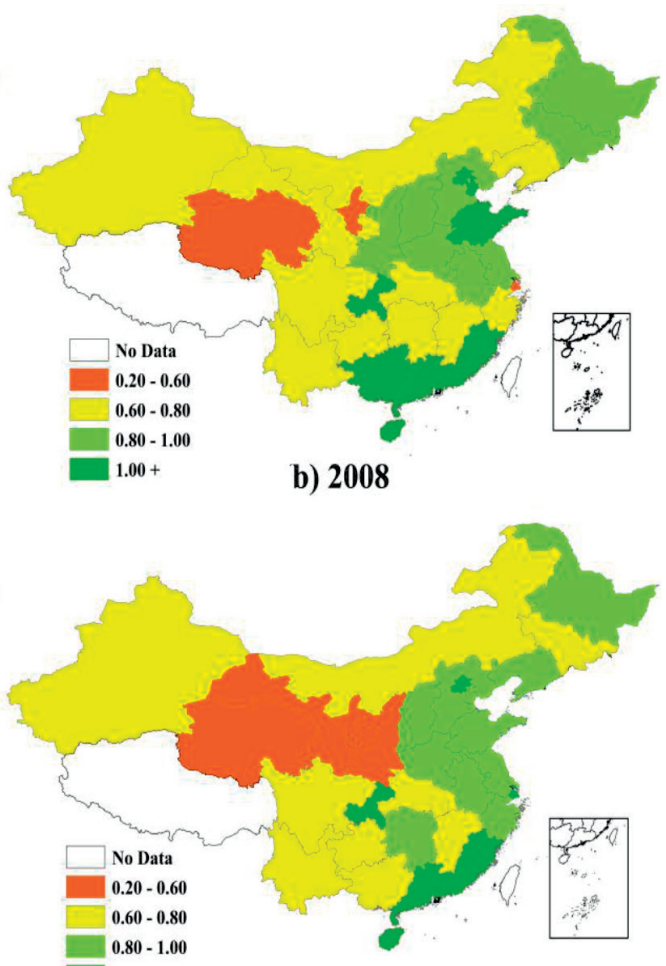

d) Geometric Mean

Fig. 1. Changes in TFEE values of provinces in China. 
the ML index to find out the leading factors affecting TFEE. TFEE values in 2001, 2008, 2016 and the TFEE value of the geometric mean are shown in Fig. 1.

On the whole, TFEE in most provinces of China showed a declining trend from 2001 to 2016, which is close to the conclusions of Fan and Wang [57], and Tao [58]. The decline in energy efficiency in the southern coastal region may be due to the implementation of the priority development strategy for coastal cities. The inflation, energy constraint and labor supply imbalance brought by the rapid economic development make TFEE show a downward trend. The gradient transfer of energy-intensive and polluting industries may be an important reason for the decrease of TFEE in the central and western regions. The energy-intensive and polluting industries in the eastern region were constantly shifting to the central and western regions, resulting in even more unreasonable industrial structure, thus leading to the continuing reduction of TFEE and the deteriorating environment in the central and western regions. Although the provinces in northwest China, such as Xinjiang, Qinghai and Gansu, are rich in energy resources, the extensive use of energy due to the remote location, low technical level and lack of capital investment, etc., hinders the improvement of TFEE and even presents a downward trend.

In Fig. 1, six provinces' TFEE geometric means are greater than or equal to 1, namely Beijing, Hainan,
Shanghai, Chongqing, Fujian and Guangdong. Eleven provinces' TFEE geometric means fall into the interval $[0.8,1.0)$, namely Henan, Tianjin, Heilongjiang, Shanxi, Hunan, Anhui, Shandong, Hebei, Jiangsu, Liaoning and Zhejiang. Nine provinces' TFEE geometric means belong to the interval $[0.6,0.8)$, namely Sichuan, Jilin, Guangxi, Hubei, Jiangxi, Yunnan, Guizhou, Inner Mongolia and Xinjiang. Four provinces' TFEE geometric means are within the interval $[0,0.6)$, namely Gansu, Shaanxi, Qinghai and Ningxia. Generally speaking, provinces with the highest TFEE means are mainly located in the eastern and southern regions, provinces with the lowest TFEE means are mainly located in the western regions, and the rest are scattered in the eastern, central and western regions. It can be concluded the basic characteristic of TFEE distribution is that TFEE decreases gradually from the east to the west in China. This conclusion is the same as that obtained by Wang et al. [37] and by $\mathrm{Li}$ and $\mathrm{He}$ [42], which is "the highest in the east, the second in the middle and the worst in the west".

Fig. 2 illustrates the changing trends of TFEE in China's eight major economic regions over years (2001-2016). According to the geometric means of TFEE, ranked from the highest to the lowest, China's eight major economic regions can be listed as following order: Region4 $>$ Region2 $>$ Region3 $>$ Region1 $>$ Region6 $>$ Region7 $>$ Region5 $>$ Region8. That is to say, the southern

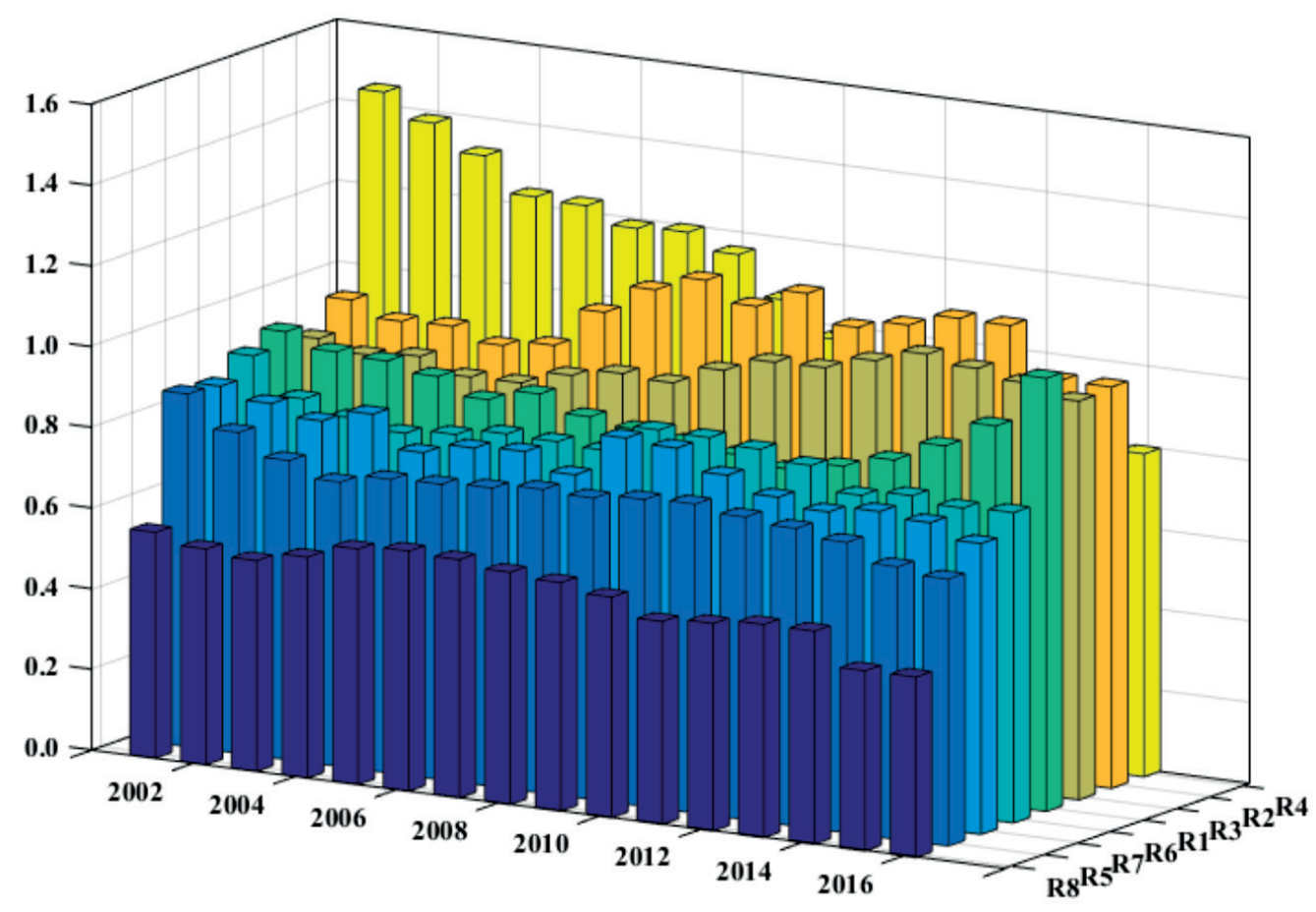

Fig. 2. Trends of TFEE in China's Eight Economic Regions over years.

Note: Region $1(R 1)$, Northeast China, including Heilongjiang, Jilin and Liaoning; Region 2 ( $R 2)$, the northern coastal region of China, including Beijing, Tianjin, Hebei and Shandong; REgion 3 (R3), the eastern coastal region of China, including Shanghai, Jiangsu and Zhejiang; Region 4 (R4), the southern coastal region of China, including Fujian, Guangdong, Hainan; Region 5 (R5), the middle reaches of the Yellow River, including Shaanxi, Shanxi, Henan, Inner Mongolia; Regron $6(R \sigma)$, the middle reaches of the Yangtze River, including Hubei, Hunan, Jiangxi, Anhui; Region 7 (R7), Southwest China, including Yunnan, Guizhou, Sichuan, Chongqing, Guangxi; Regron 8 (R8), Northwest China, including Gansu, Qinghai, Ningxia, Xizang, Xinjiang. 
Table 3. ML Index of the Eight Major Economic Regions (2002-2016).

\begin{tabular}{|c|c|c|c|c|c|c|c|c|}
\hline Year & Region1 & Region2 & Region3 & Region4 & Region5 & Region6 & Region7 & Region8 \\
\hline 2002 & 0.9004 & 0.8848 & 1.0046 & 1.0653 & 0.9771 & 1.0024 & 0.9822 & 1.0152 \\
\hline 2003 & 0.9606 & 0.9859 & 0.9892 & 0.9514 & 1.0388 & 1.0098 & 1.0283 & 0.9883 \\
\hline 2004 & 0.9633 & 0.9847 & 1.0514 & 1.0350 & 0.9294 & 1.0138 & 1.0071 & 1.0081 \\
\hline 2005 & 0.9804 & 0.9990 & 1.0229 & 1.0246 & 1.1001 & 1.0337 & 1.0276 & 1.0489 \\
\hline 2006 & 0.9986 & 1.0026 & 0.9916 & 0.9661 & 1.0109 & 1.0215 & 1.0113 & 1.0405 \\
\hline 2007 & 0.9908 & 1.0027 & 0.9988 & 0.9401 & 0.9926 & 0.9970 & 0.9388 & 1.0501 \\
\hline 2008 & 1.0051 & 1.0224 & 0.9757 & 1.0200 & 0.9473 & 1.0056 & 1.0173 & 0.9929 \\
\hline 2009 & 1.0075 & 1.0029 & 0.9919 & 0.9931 & 0.9685 & 1.0215 & 1.0549 & 0.9854 \\
\hline 2010 & 1.0001 & 1.0030 & 0.9806 & 0.9921 & 1.0100 & 0.9989 & 0.9937 & 0.9841 \\
\hline 2011 & 1.0065 & 0.9711 & 0.9864 & 1.0042 & 1.0194 & 0.9969 & 0.9984 & 0.9769 \\
\hline 2012 & 0.9883 & 1.0145 & 0.9804 & 1.0071 & 1.0152 & 1.0209 & 1.0527 & 0.9775 \\
\hline 2013 & 0.9315 & 1.0112 & 1.0158 & 1.0412 & 0.9534 & 1.0340 & 1.0456 & 1.0014 \\
\hline 2014 & 0.9672 & 0.9970 & 1.0170 & 1.0250 & 1.0182 & 1.0107 & 0.9930 & 1.0112 \\
\hline 2015 & 0.9900 & 0.9391 & 1.0372 & 1.0071 & 1.0379 & 1.0318 & 1.0779 & 0.9800 \\
\hline 2016 & 0.9946 & 1.0905 & 0.9951 & 0.9321 & 0.9830 & 0.9958 & 1.0401 & 0.9862 \\
\hline Means & 0.9786 & 0.9932 & 1.0023 & 0.9996 & 0.9993 & 1.0129 & 1.0174 & 1.0028 \\
\hline
\end{tabular}

coastal region has the highest TFEE value, followed by the northern coastal region, the eastern coastal region, the northeast region, the middle reaches of the Yangtze River, the southwest region and the middle reaches of the Yellow River. The TFEE value in the northwest region is the lowest. In addition, except for Region1, Region2 and Region3, TFEE values in other economic regions tend to decrease over time.

Table 3 shows the ML index and the geometric means of China's eight major economic regions over years (2002-2016). As can be seen from Table 3, the geometric means of Region3, Region6, Region7 and Region8 are greater than 1; the geometric means of other Regions are all less than 1. It indicates that, on average, the energy efficiencies of Region 3, Region 6, Region 7 and Region 8 are progressive, while those of the other four economic regions are regressive.

Fig. 3 shows Zofio decomposition results of ML index of the eight major economic regions, where PEC represents pure efficiency change, PTC represents pure technology change, SEC represents scale efficiency change, and STC represents scale technology change. As can be seen from Fig. 3, Region3, Region4, Region5, Region6, Region7 and Region8 have progressed in pure efficiency; Region1 and Region2 have regressed in pure efficiency. In terms of pure technological change (PTC), only Region2 grows, and other economic regions decrease to some degree. As for scale efficiency change (SEC), only Region2 and Region4 increase, while the others decrease to different degrees. In terms of scale technology change (STC), Region1, Region3, Region5 and Region8 increase, while the remaining regions decrease. A conclusion can be drawn that, in general, pure technological change (PTC) has a key impact on the improvement of the energy efficiency in the eight major economic regions. In line with our conclusion, Qi and Tao [47] also concluded in their study that PTC played a leading role in promoting energy efficiency.

\section{Quantitative Analysis of Influencing Factors}

In order to distinguish the dominant factors that affect the total factor energy efficiency (TFEE) in

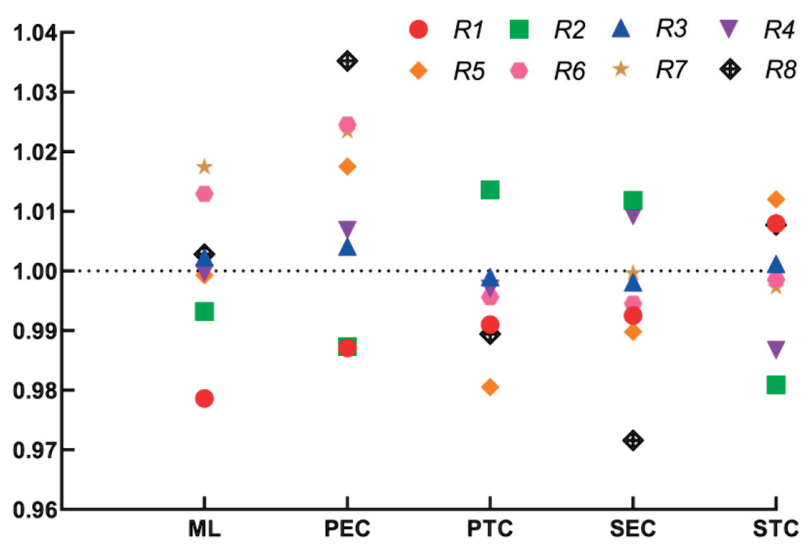

Fig. 3. ML Index and Decomposition of Eight Major Economic Regions. 
Table 4. Descriptive Statistics of Variables.

\begin{tabular}{|c|c|c|c|c|c|c|}
\hline & TFEE & PGDP & COAL & SEC & TER & TECH \\
\hline Mean & 0.8560 & 2.9692 & 0.4598 & 0.4596 & 0.4192 & 0.0092 \\
\hline Median & 0.8186 & 2.4544 & 0.4636 & 0.4749 & 0.4046 & 0.0035 \\
\hline Maximum & 2.1781 & 11.8128 & 0.7618 & 0.5905 & 0.8023 & 0.1535 \\
\hline Minimum & 0.3507 & 0.2983 & 0.0679 & 0.1926 & 0.2830 & 0.0001 \\
\hline Std. Dev. & 0.2729 & 2.1677 & 0.1286 & 0.0783 & 0.0821 & 0.0196 \\
\hline Skewness & 1.5061 & 1.2331 & -0.2131 & -1.1330 & 2.2914 & 5.1444 \\
\hline Kurtosis & 6.7136 & 4.4562 & 2.9645 & 4.2561 & 9.7266 & 32.4475 \\
\hline
\end{tabular}

China's eight major economic regions, Tobit model is used for quantitative analysis.

The influencing factors of TFEE are examined from the four aspects: the economic development level, the energy consumption structure, the industrial structure, and the technology development. The economic development level is measured by GDP per capita (abb. PGDP, unit: ten thousand Yuan per capita, expected symbol ,,+"). The energy consumption structure is measured by the proportion of coal in energy consumption (abb. COAL, unit: \%, expected symbol ,-“). The industrial structure is measured by the ratio of the added value of the secondary industry to GDP (abb. SEC, unit: \%, expected symbol ,-“), and the ratio of the added value of the tertiary industry to GDP (abb. TER, unit: \%, expected symbol ,,“). The technology development is measured by the proportion of technology market turnover in GDP (abb. TECH, unit: \%, expected symbol ,,+“). Descriptive statistics of variables in the model are shown in Table 4.

The following Tobit regression equation is established, and the regression results are shown in Table 5.

$T F E E=c+\beta_{1} P G D P+\beta_{2} C O A L+\beta_{3} S E C+\beta_{4} T E R+\beta_{5} T E C H$

As can be seen from Table 5, all the variables except for COAL have passed the significance test at the level of $5 \%$. The regression coefficients of two variables (COAL, SEC) are negative, and those of other variables are positive. The positive and negative influences of these five variables on TFEE are exactly the same as expected.

From the regression results, TECH has the most significant impact on TFEE, with a coefficient of 4.1826, and passes the significance test at the level of $1 \%$. It means that the proportion of technology market turnover in GDP is positively related to TFEE. If TECH increases by one unit, TFEE will increase by 4.1826 units.

The second important factor is TER, with a coefficient of 0.4548 . It indicates that the ratio of the added value of the tertiary industry to GDP is positively related to TFEE. If TER increases by 1 unit, TFEE will increase by 0.4548 units.

The third relatively important influencing factor is SEC with a coefficient of-0.3854. It shows that the proportion of the added value of the secondary industry in GDP is negatively related to TFEE. If SEC increases by one unit, TFEE will decrease by 0.3854 units.

As for the influencing factor COAL, with a coefficient of -0.0778 , it means the proportion of coal in energy consumption is negatively correlated with TFEE. If COAL increases by 1 unit, TFEE will decrease by 0.0778 units. However, the significance level of COAL is 0.4359 , without passing the significance test, which indicates that COAL does not play a significant role in the regression equation, unlike the findings of Chen

Table 5. Regression Results of Tobit Model.

\begin{tabular}{|c|c|c|c|c|}
\hline & Coefficient & Std. Error & z-Statistic & Prob. \\
\hline C & 0.8152 & 0.2025 & 4.0259 & $0.0001^{* * *}$ \\
\hline PGDP & 0.0083 & 0.0074 & 1.1290 & $0.0489^{* *}$ \\
\hline COAL & -0.0778 & 0.0998 & -0.7792 & 0.4359 \\
\hline SEC & -0.3854 & 0.2243 & -1.7184 & $0.0157^{* *}$ \\
\hline TER & 0.4548 & 0.3088 & 1.4726 & $0.0000^{* * *}$ \\
\hline TECH & 4.1826 & 0.8568 & 4.8818 & $0.0000^{* * *}$ \\
\hline
\end{tabular}

Note: ${ }^{* * *}$ and ${ }^{* *}$ indicate significant levels at the $1 \%$ and $5 \%$,respectively. 
[20] and $\mathrm{Li}$ and He [42]. This seems to be inconsistent with the general understanding of the public. In fact, there is a deep-seated reason behind it. The current energy consumption in China is dominated by coal. For each province, the high proportion of coal is a common influence, so its role is not highlighted in the equation.

The coefficient of the last influencing factor PGDP is 0.0083 , the smallest one among all regression coefficients (absolute values), which means that the influence of GDP per capita on TFEE is also minimal in comparison.

From the above analysis, it can be seen that the dominant factors affecting TFEE in China's eight major economic regions are the technological development and the industrial structure, while the economic development level and the energy consumption structure are relatively less important. Although energy consumption structure is not significant, it reflects the abnormal structure of coal-based energy consumption in China. Based on these results, the following targeted recommendations are put forward.

(1) Pay close attention to the technological development. Technology is the primary productive force and also contributes to improving energy efficiency. At the regional level, each economic region should pay more attention to the development of technology, continuously increase investments in technological progress, and upgrade the existing outdated industrial technologies as soon as possible. At the national level, the central government should formulate relevant policies to stimulate the enthusiasm of local governments to develop technology. Through the guidance of relevant policies, all provinces are encouraged to devote themselves to knowledge innovation and technological innovation, and improve their technological level continuously, especially the high-tech level.

(2) Adjust the industrial structure. All economic regions should make efforts to develop the tertiary industry and increase the proportion of the added value of the tertiary industry in GDP gradually. In the southern coastal region (Fujian, Guangdong and Hainan) the tertiary industries are developed well. Especially in Hainan province, tourism has vigorously developed in recent years. It is mainly the rise of the tertiary industry that makes the energy efficiency of the southern coastal region rank first among the eight major economic regions. The northwest region (Gansu, Qinghai, Ningxia and Xinjiang) has harsh natural conditions, the development level of its tertiary industry lags behind obviously, and its total factor energy efficiency (TFEE) is the lowest among the economic regions. The northwest region should learn from the southern coastal region in the efforts to develop characteristic tourism vigorously, and optimize its industry structure. Other economic regions should also vigorously develop the tertiary industry in the process of economic development, reducing the proportion of the secondary industry, and gradually optimize their own industry structures.

(3) Improve the energy consumption structure. China's energy endowment is characterized by more coal, less oil and less gas, which determines that China's energy consumption is generally dominated by coal. Therefore, for each economic region, if it takes the lead in developing and using clean and renewable energy, then it will gain outstanding advantages. Fortunately, China is currently working on the application of integrated energy system, which can effectively utilize all kinds of clean energy. Under this background, photovoltaic power generation and wind power generation can be vigorously developed in the western economic region, and offshore wind power generation can be promoted in the northern, eastern and southern coastal regions. Other regions are rich in straw resources and can vigorously develop biomass power generation technology and biodiesel technology.

\section{Conclusions}

It plays an important role in China's energy conservation, emission reduction and ecological protection to study TFEE in China's eight major economic regions. Based on the panel data, TFEE values of 30 provinces over years are calculated via super-efficiency SBM model. The results show that TFEE values in China basically show the rule of low in the west and high in the east. TFEE values in the southern, northern and eastern coasts rank the top three, followed by the northeast, the middle reaches of the Yangtze River, the southwest and middle reaches of the Yellow River, with the lowest TFEE value in the northwest.

Zofio decomposition is carried out on ML index of China's eight major economic regions. The results show that Region3, Region4, Region5, Region6, Region7 and Region8 increase in the pure efficiency (PEC); Region1 and Region2 deteriorate in the pure efficiency (PEC). Only the pure technological change (PTC) of Region2 is increasing, while those of other economic regions are decreasing to varying degrees. In terms of scale technology change (STC), Region1, Region3, Region5 and Region8 are increasing, while the rest are decreasing. From the above, it can be seen that only the northern coastal region (including Beijing, Tianjin, Hebei and Shandong) has seen their pure technological changes increasing while the others have seen the opposite. Therefore, it is of great significance to improve pure technological changes for improving TFEE in China as a whole.

In order to build Tobit regression model, we select TFEE as a dependent variable, and GDP per capita (PGDP), COAL's share in energy consumption (COAL), the proportion of added value of secondary industry in GDP (SEC), the proportion of added value of tertiary industry in GDP (TER) and the proportion of technology 
market turnover in GDP as independent variables. The model explores the dominant factors affecting TFEE from four aspects: the economic development level, the energy consumption structure, the industrial structure, and the technological development. Results show that the dominant factors affecting TFEE are the technological development and the industrial structure, while the economic development level and the energy consumption structure have no significant influences. The results are consistent with Zofio decomposition.

\section{Acknowledgments}

We gratefully acknowledge the financial support from the Hebei Social Science Fund (HB17GL068) and the Fundamental Research Funds for the Central Universities (2018MS143).

\section{Conflict of Interests}

The authors declare no conflict of interest.

\section{References}

1. FENG S., XU C.L. Summary of Development of Global Climate Change and Its Effects on Social Economy. China Population, Resources and Environment. 24 (S2), 6, 2014.

2. LIN Z.Q. Medium and Long-term Development Strategy of China's Energy \& Environment. China Soft Science. 12, 45-57, 2013.

3. RITTER H., SCHOPF M. Unilateral Climate Policy: Harmful or Even Disastrous?. Working Papers CIE. 58 (1), 155, 2014.

4. China National Bureau of Statistics, Statistical Bulletin of the People's Republic of China on National Economic and Social Development in 2017. Available online: http://www. stats.gov.cn/tjsj/zxfb/201802/t20180228_1585631.html. (accessed on 15/1/2019)

5. BP. Statistical Review of World Energy. Available online: https://www.bp.com/content/dam/bp/business-sites/ en/global/corporate/pdfs/energy-economics/statisticalreview/bp-stats-review-2018-full-report.pdf. (accessed on 15/1/2019)

6. BP. Statistical Review of World Energy. Available online: https://www.bp.com/content/dam/bp/business-sites/en/ global/corporate/pdfs/energy-economics/energy-outlook/ bp-energy-outlook-2018-country-insight-china.pdf. (accessed on 15/1/2019)

7. PATTERSON M.G. What is energy efficiency? : Concepts, indicators and methodological issues. Energy Policy. 24 (5), 377, 1996.

8. SHI D. Regional Differences in China's Energy Efficiency and Conservation Potential. China Industrial Economic. 10, 49, 2006.

9. HU J.L., WANG SHIH-CHUAN Total-factor Energy Efficiency of Regions in China. Energy Policy. 34 (17), 3206, 2006.

10. KANG H.Y., SUN Y.L., CHEN Z.H. An Empirical Analysis of the Total Factor Productivity Change and
Convergence of China's Provincial Energy. Statistics \& Decision. 05, 101, 2016.

11. MA X.J., WANG C.X., YU Y.B., LI Y.D., DONG B.Y. ZHANG X.Y., NIU X.Q., YANG Q., CHEN R.M., LI Y.F. Ecological efficiency in China and its influencing factors a super-efficient SBM metafrontier-Malmquist-Tobit model study. Environ. Sci. Pollut. R. 25 (21), 20880, 2018.

12. LUO Y.Y., YIN L., QIN Y., WANG Z., GONG Y.F. Evaluating Water Use Efficiency in China's Western Provinces Based on a Slacks-Based Measure (SBM)Undesirable Window Model and a Malmquist Productivity Index. Symmetry. 10 (8), 301, 2018.

13. DU K.R., LIN B.Q. International comparison of total-factor energy productivity growth: A parametric Malmquist index approach. Energy. 118, 481, 2017.

14. WANG L.W., LE KE-DUC, NGUYEN THI-DUONG Assessment of the Energy Efficiency Improvement of Twenty-Five Countries: A DEA Approach. Energies. 12, 1535, 2019

15. YU C., KANGJUAN LV, JIAN W., HAO X. Energy efficiency, carbon dioxide emission efficiency, and related abatement costs in regional China: a synthesis of inputoutput analysis and DEA. Energ Effic. 12 (4), 863, 2018.

16. LIU Y.N., WANG K. Energy efficiency of China's industry sector: An adjusted network DEA (data envelopment analysis)-based decomposition analysis. Energy. 93, 2015.

17. HU J.L., HONMA S. A Comparative Study of Energy Efficiency of OECD Countries: An Application of the Stochastic Frontier Analysis. Energy Procedia. 61, 2280, 2014.

18. FENG C., WANG M., ZHANG Y., LIU G.C. Decomposition of energy efficiency and energy-saving potential in China: A three-hierarchy meta-frontier approach. J. Clean Prod. 176, 1054, 2018.

19. ZHAO J. L., LI G., SU Q., LIU J.G. Regional Differences and Convergence Analysis of Energy Efficiency in China: on Stochastic Frontier Analysis and Panel Unit Root. Chinese Journal of Management Science. 21 (02), 175, 2013.

20. CHEN G.J. Research on Total Factor Energy Efficiency of Chinese Manufacture Industry and Its Influence Factors Based on SFA. China Soft Science. 01, 180, 2014.

21. CHEN W., HE R., WU Q. A Novel Efficiency Measure Model for Industrial Land Use Based on Subvector Data Envelope Analysis and Spatial Analysis Method. Complexity. 2017, 1, 2017.

22. DONG F., YU B.L., HADACHIN T., DAI Y.J., WANG Y., ZHANG S.N., LONG R.Y. Drivers of carbon emission intensity change in China. Resources, Conservation and Recycling. 129, 187, 2018.

23. KHOSHROO A., IZADIKHAH M., EMROUZNEJAD A. Improving energy efficiency considering reduction of $\mathrm{CO}_{2}$ emission of turnip production: A novel data envelopment analysis model with undesirable output approach. J. Clean Prod. 187, 605, 2018.

24. BANG YOU-YOUNG, LEE D.S., LIM SEONG-RIN Analysis of corporate $\mathrm{CO}_{2}$ and energy cost efficiency: The role of performance indicators and effective environmental reporting. Energy Policy. 133, 2019.

25. YANG Z.S., WEI X.X. Total factor energy efficiency of the regions along the belt and road: Measurement, decomposition and influence factors analysis. China Environmental Science. 38 (11), 4384, 2018.

26. LIU D., ZHAO S., GUO Y. Energy efficiency and its determinants of western China: total perspective. China Environmental Science. 35 (06), 1911, 2015. 
27. DE CASTRO CAMIOTO F., MORALLES H.F., MARIANO E.B., REBELATTO D.A. Energy efficiency analysis of G7 and BRICS considering total-factor structure. J. Clean Prod. 122, 67, 2016.

28. CHOI KI-HONG, OH W. Extended Divisia index decomposition of changes in energy intensity: A case of Korean manufacturing industry. Energy Policy. 65, 275, 2014.

29. FANG C.L., LUO K., KONG Y.L., LIN H.X., REN Y.F. Evaluating Performance and Elucidating the Mechanisms of Collaborative Development within the Beijing-TianjinHebei Region, China. Sustainability. 10 (2), 471, 2018.

30. APERGIS N., AYE G.C., BARROS C.P., GUPTA R., WANKE P. Energy efficiency of selected OECD countries: A slacks based model with undesirable outputs. Energ Econ. 51, 45, 2015.

31. WANG K., WEI Y.M. China's regional industrial energy efficiency and carbon emissions abatement costs. Appl Energ. 130, 617, 2014

32. ZHANG W., WU W.Y. Research on Total-factor Energy Efficiency of Metropolitan Regions of Yangtze River Delta Based on Environmental Performance. Economic Research Journal. 46 (10), 95, 2011.

33. ANDERSEN P., PETERSEN N.C. A Procedure for Ranking Efficient Units in Data Envelopment Analysis. Manage Sci. 39 (10), 1261, 1993.

34. YI L., NIU D.X., ZHOU W., FAN Y. Decomposition Analysis of Carbon Emissions from Energy Consumption in Beijing-Tianjin-Hebei, China: A Weighted-Combination Model Based on Logarithmic Mean Divisia Index and Shapley Value. Sustainability. 10 (7), 2535, 2018.

35. MA X.M., YAN K.X. Comprehensive Evaluation of Interprovincial Energy Efficiency in China During the "Twelfth Five-Year Plan" Period and Analysis of Its Influencing Factors. Science and Technology Management Research. 38 (23), 50, 2018.

36. HUANG G.Q., BAI L.B. Study on Industrial Energy Efficiency and Influencing Factors in Shananxi Province: Based on Three-Stage Super-Efficiency DEA Model. Ecol Econ. 35 (04), 58, 2019.

37. WANG B., ZHANG J. H., ZHANG H. Total-Factor Energy Efficiency and Influencing Factors across Provinces in China in the Presence of Environmental Regulation. Econ Rev. 04, 31, 2011.

38. SONG X., KUANG X.M. Is the Development of Service Sector is Beneficial to Improve Resource Utilization and Environmental Protection? - Based on the Perspective of Energy Efficiency. Reform of Economic System. 03, 179, 2018.

39. LIU H.M., ZHANG Z.X., WANG L.Y. Study on Energy Efficiency and Influencing Factors of Chinese Provinces From Perspective of Supply Side. Statistics \& Decision. 34 (22), 131, 2018.

40. YAN H.J. Provincial energy intensity in China: The role of urbanization. Energy Policy. 86, 2015.

41. MA B. Does urbanization affect energy intensities across provinces in China? Long-run elasticities estimation using dynamic panels with heterogeneous slopes. Energ Econ. 49, 2015

42. LI F., HE L.Z. Research on Total Factor Energy Efficiency Measurement and Its Influential Factors in China under the Constraint of Carbon Emission. Ecol Econ. 33 (05), 35, 2017.
43. WANG Q., YUAN B.L. Air pollution control intensity and ecological total-factor energy efficiency: The moderating effect of ownership structure. J. Clean Prod. 186, 2018.

44. WU J., ZHU Q. Y., YIN P.Z., SONG M. Measuring energy and environmental performance for regions in China by using DEA-based Malmquist indices. Oper Res-ger. 17 (3), 715, 2017.

45. LIU J.P., YANG Q.R., HE L. Total-Factor Energy Efficiency (TFEE) Evaluation on Thermal Power Industry with DEA, Malmquist and Multiple Regression Techniques. Energies. 10 (7), 1039, 2017.

46. MA X. J., LIU Y., WEI X.X., LI Y.F., YU Y.B. Measurement and decomposition of energy efficiency of Northeast China - based on super efficiency DEA model and Malmquist index. Environ Sci Pollut R. 24 (6), 19859, 2017.

47. QI Y.W., TAO C.Q. Measurement and Decomposition of Environmental Total Factor Productivity Growth in China's Regional Economies. Shanghai Journal of Economics. 24 (10), 3, 2012.

48. JIN C.Y., WANG W.Q. Research on Differences Exits of Total Factor Productivity Growth in Three Major Urban Agglomerations of China under Environmental Constraint: Based on Global Malmquist-Luenberger Index. Shanghai Journal of Economics. 01, 3, 2016.

49. CHEN G.C., LIU H.N., YU S.H. Analysis on the Total Factor Productivity of Southwest Frontier Area underthe Constraint of Income Gap - Based on MalmquistLuenberger Index. Journal of Guangxi Normal University (Philosophy and Social Sciences Edition). 52 (06). 54, 2016.

50. ZHU L.Y., MA D., ZENG Z.C. Green Total Factor Productivity Research of Iron and Steel Enterprise Based on the Network Malmquist-Luenberger Index - A case study on iron and steel enterprises of Hebei province. Mathematics in Practice and Theory. 47 (19), 146, 2017.

51. APARICIO J., RUIZ J.L., SIRVENT I. Closest targets and minimum distance to the Pareto-efficient frontier in DEA. Journal of Productivity Analysis. 28 (3), 209, 2007.

52. WANG L., CHEN Z.C., MA D., ZHAO P. Measuring Carbon Emissions Performance in 123 Countries: Application of Minimum Distance to the Strong Efficiency Frontier Analysis. Sustainability. 5 (12), 5319, 2013.

53. COOPER W.W., RUIZ J.L., SIRVENT I. Choosing weights from alternative optimal solutions of dual multiplier models in DEA. Eur J Oper Res. 180 (1), 443, 2007.

54. ZOFIO J.L. Malmquist productivity index decompositions: a unifying framework. Appl Econ. 39 (18), 2371, 2007.

55. JIMÉNEZ-SÁEZ F., ZABALA-ITURRIAGAGOITIA J.M., ZOFÍO J.L. Who leads research productivity growth? Guidelines for R\&D policy-makers. Scientometrics. 94 (1), 273, 2013.

56. MILLAR R.B. Maximum likelihood estimation and inference. With examples in R, SAS and ADMB. 2011.

57. FAN Q.F., WANG L.Y. Total Factor Energy Efficiency and Regional Difference in China - Based on BCC and Malmquist Model. Journal of Industrial Technological Economics. 37 (12), 61, 2018.

58. TAO C.Q., LI C., WANG X.H. Suitability of environmental regulation effect on total-factor energy efficiency and relation to energy consumption structure evolution. China Population, Resources and Environment. 28 (04), 98, 2018. 